\title{
Extremely rare case report of chronic inversion of uterus with submucous fundal fibroid with dragging of bladder wall and ureters along with: a case report and review of literature
}

\author{
Rajshree D. Katke* \\ Department of Obstetrics \& Gynecology, Cama \& Albless Hospital, Grant Government Medical College \& Sir J. J. \\ Group of Hospitals, Mumbai-400001, Maharashtra, India \\ Received: 12 April 2014 \\ Accepted: 4 May 2014 \\ *Correspondence: \\ Dr. Rajshree D. Katke, \\ E-mail: drrajshrikatke@gmail.com \\ (C) 2014 Katke RD. This is an open-access article distributed under the terms of the Creative Commons Attribution \\ Non-Commercial License, which permits unrestricted non-commercial use, distribution, and reproduction in any \\ medium, provided the original work is properly cited.
}

\begin{abstract}
Non-puerperal chronic uterine inversion is a very rare entity, usually precipitated by tumours sited at the fundus of the uterus which exert traction force to cause the inversion. Here we are presenting a case of 55 year postmenopausal female P7L2D5 with non-puerperal chronic uterine inversion with fundal fibroid which has caused dragging of urinary bladder wall in it which is a rarest entity. Exploratory laparotomy was done with proper dissection at bladder and ureters to prevent the injury. Safely hysterectomy was done after cutting the rim of the cup. Histopathology was suggestive of leiomyoma with chronic cervicitis. Post-operative course in ward was uneventful and patient could go back to work.
\end{abstract}

Keywords: Chronic uterine inversion, Non-puerperal uterine inversion

\section{INTRODUCTION}

Uterine inversion refers to descent of the uterine fundus to or through the cervix, so that the uterus is turned inside out. Uterine inversion is a rare condition that occurs usually as a complication of deliveries. Non-puerperal inversion is extremely rare representing about one sixth of all inversion. Chronic non puerperal uterine inversion is often associated with uterine pathology. Prolapsed fibroids tend to be the most common inciting factors with occasional report of inversion associated with uterine neoplasm and endometrial polyp.

\section{CASE REPORT}

A 55 year old postmenopausal woman came to our outpatient department with complaints of something coming out of vagina and white discharge since last 2-3 years. She was postmenopausal since last 6 years. Patient was
P7D5L2. She did not have any past abnormal medical and surgical history. On general examination she was pale and there was no edema or icterus. Her respiratory and cardiovascular systems were normal. On per abdominal examination it was soft, nontender. There was no palpable pathology.

On local examination no mass was seen outside vagina. On per speculum examination, there was mass of $7 \mathrm{~cm} \mathrm{x}$ $6 \mathrm{~cm} \times 5 \mathrm{~cm}$ protruding in the vagina; the lower part of the mass was edematous unhealthy, congested and red in the appearance. On per vaginum examination, the same mass was felt protruding in the vagina. The mass was firm in consistency, with smooth outline. Cervical rim felt was very high up. Fundus was not felt; there was a dimple which was felt. Fornices appeared to be normal. Tenderness was present. The provisional diagnosis was of chronic inversion or fibroid polyp. Her hematological investigations were normal except hemoglobin $9 \mathrm{gm} \%$. 
Her renal and liver functions, ECG, X-ray chest were normal. She was given oral antibiotics and locally cleaning with betadine douches. Local signs of the mass were improved with treatment. Edema and congestion of the mass got reduced.

On ultrasound examination uterus was $10 \mathrm{~cm} \mathrm{x} 8 \mathrm{~cm} \mathrm{x} 3$ cm bulky. ET $12.4 \mathrm{~mm}$, cervical. Lower segment showed well defined mixed $6.5 \mathrm{~cm}$ x $4.5 \mathrm{~cm}$ x $3 \mathrm{~cm}$ polypoidal growth in the cervical region. Patient's MRI (Magnetic Resolution Imaging), showed complete Inversion of uterus with large fundal submucosal polyp. Bilateral ureters were normal but very close to the polyp. Bladder appeared to be normal. As the mass was protruding in the vagina but the rim was very high up and not able to palpate easily and on MRI the close proximity and dragging of ureter close to it was seen with consequent complication of genitourinary system; the decision of exploratory laparotomy was taken. Under epidural and general anesthesia patients' abdomen opened in layers. After opening the peritoneum; findings in situ were as follows. There was absent uterine fundus. Both the round ligaments had gone in to the dimple. Along with it both the ovaries had gone inside. The urinary bladder wall was dragged in the cupping. The rugosity of the bladder wall which has gone inside was looking very much prominent, slightly congested and edematous. Both the ureters were dragged closely to the sides of the cupping site. It was a classical-mouth of the flowerpot appearance.

After examining the anatomical position of the bladder and both the ureters, the surgery started with the holding both the round ligaments clamped, cut and ligated. Then fold of broad ligament opened both the ureters identified and with fine dissection and separation are displaced more laterally. The part of the urinary bladder dragged inside taken out of the cup by opening the fold of peritoneum over it and taking out the separated bladder wall by the fingers.

Now the anatomy was clearly seen. At the cupping there was tight ring felt, after confirming the all organs in the vicinity away of it the rim was felt properly then it was cut posteriorly. At the same time the vaginal part of the inverted part of the uterus had pushed up from vagina after cutting the thick posterior cervical ring rim. Then the hysterectomy of the pulled up inverted uterus lined by endometrial lining with fundal submucous fibroid was completed by clamping, cutting and ligating the both uterine, uterosacrals.

The specimen was taken out. Vagina was closed in layers after achieving complete hemostasis and ensuring the counts. Patient withstood surgery well. Her postoperative period was uneventful. Stiches were taken out. Wound healthy. Patient discharged on $12^{\text {th }}$ day. Her histopathology report revealed fundal submucosal fibroid polyp with uterine inversion. Patient came for follow up and she was fine.

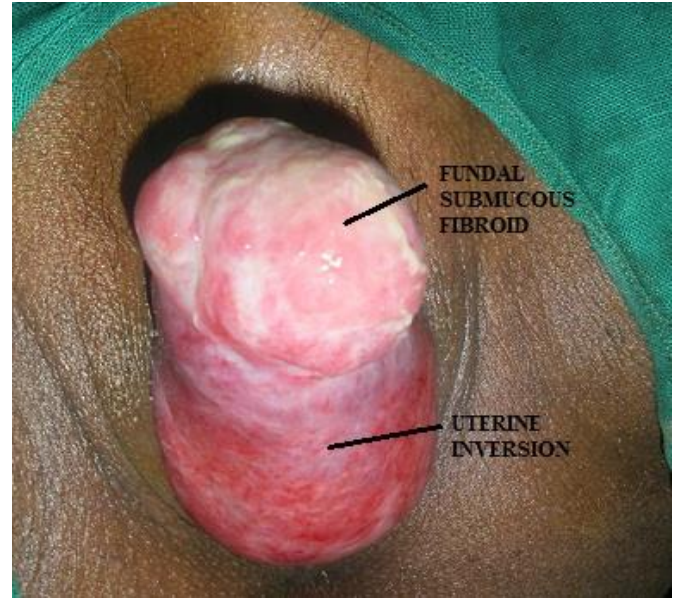

Figure 1: MRI showed complete inversion of uterus with large fundal submucosal polyp.

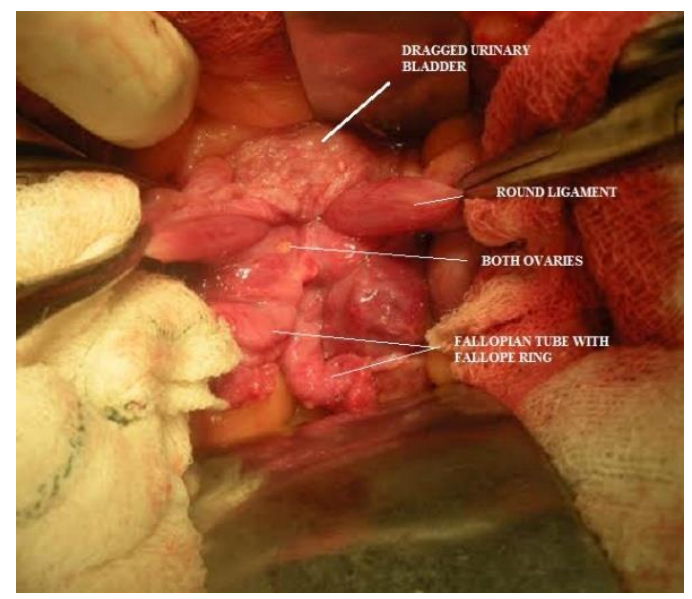

Figure 2: Shows dragged urinary bladder, round ligament, both ovaries and fallopian tube with Falope ring.

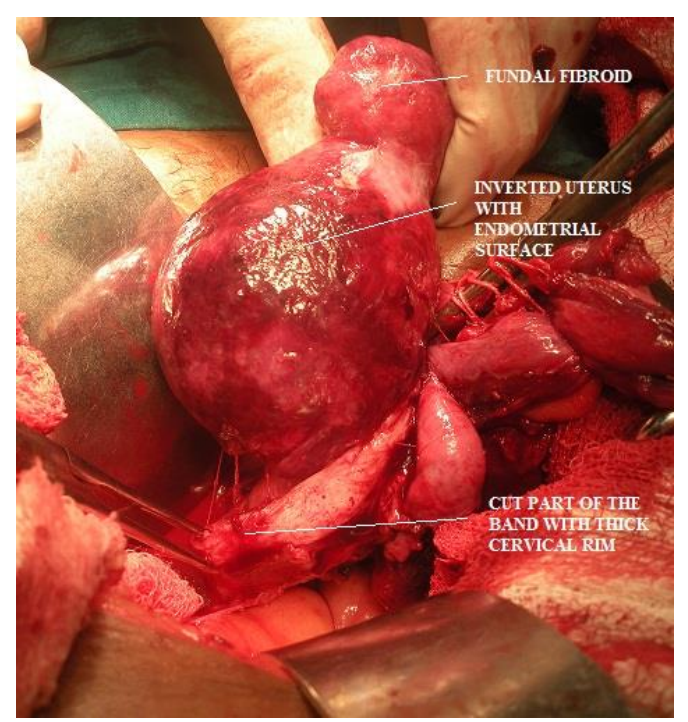

Figure 3: Shows fundal fibroid with endometrial surface and cut part of band with thick cervical rim. 


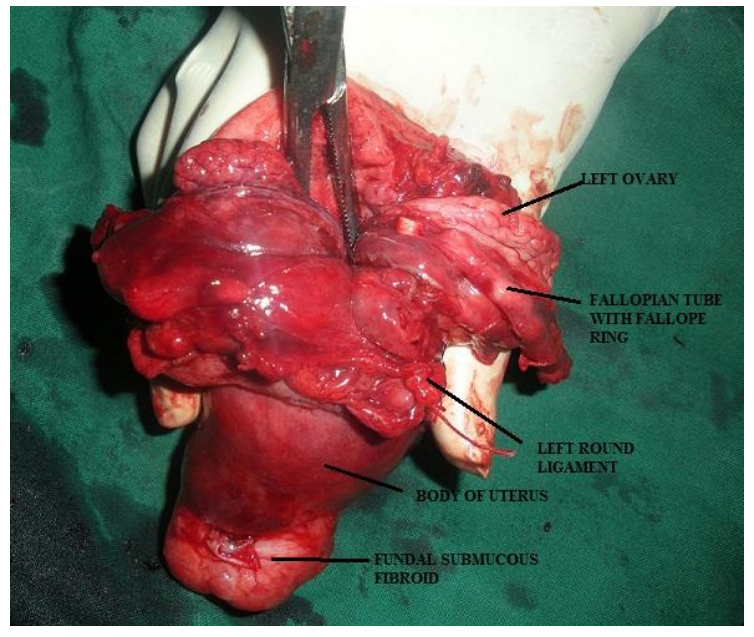

Figure 4: Shows clear anatomy of genitourinary system.

\section{DISCUSSION}

Uterine inversion refers to descent of the uterine fundus to or through the cervix, so that the uterus is turned inside out. Uterine inversion is a rare condition that occurs usually as a complication of deliveries, occurs in early postpartum

1. Non-puerperal inversion is extremely rare representing about one sixth of all inversion.

2. Chronic non puerperal uterine inversion is often associated with uterine pathology. Prolapsed fibroids tend to be the most common inciting factors with occasional report of inversion associated with uterine neoplasm and endometrial polyp.

Uterine leiomyoma were known to cause uterine inversion in $78.8 \%-85 \%$ of cases and was the most common cause. ${ }^{2,3}$

Three contributing factors proposed for uterine inversion are (1) sudden emptying of the uterus which was previously distended by a tumor (2) thinning of the uterine walls due to an intrauterine tumor and (3) dilatation of cervix.

Uterine inversions can be classified as follows:

Stage 1: The inverted fundus remains in the uterine cavity

Stage 2: Complete inversion of the fundus through the cervix

Stage 3: The inverted fundus protrudes through the vulva

Stage 4: Inversion of the uterus and the vaginal wall through thevulva. ${ }^{4}$

Inversion can also be classified as acute and chronic. Acute uterine inversion causes severe pain and hemorrhage whereas chronic inversion is insidious and characterized by pelvic discomfort, vaginal discharge, irregular vaginal bleeding and anemia. In acute inversion the uterus can be generally reverted by intravaginal manipulation. The diagnosis is easier with a stage 3 or 4 disease when a bluish-red mass is identified from the vulva. In other cases, the diagnosis can be difficult and the use of ultrasound or computer tomography can be used. The clinical diagnosis of chronic inversion depends on finding a mass coming through the cervix, without definite margins of a cervix, and the absence of the uterine body during bimanual or rectal examinations. Openings of the fallopian tubes may be identifiable on its endometrial surface. Indentation of the fundal area and a depressed longitudinal grove extending from the uterus to the centre of the inverted uterus are the two signs described in relation to the chronic uterine inversion.

In chronic uterine inversions, surgery is imperative. Many surgical methods have been described to treat chronic non puerperal uterine inversion. The efficacy of the nonsurgical methods is not clear. Huntington and Haultain are commonly used abdominal approaches; whereas Kustner and Spinelli procedures are the commonly used vaginal approaches. ${ }^{5,6}$ Spinell's approach is anterior and requires dissection of the bladder and an anterior uterine wall incision, while Kustner's is a posterior approach with incision on the posterior uterine wall. Huntington procedure consists in locating the cup of uterus formed by the inversion, dilating the cervical ring digitally, and gentle upward traction of the round ligaments of the uterus. The Haultaim procedure uses a vertical incision in the post portion of the ring (which ring) and gentle traction on the round ligaments.

\section{CONCLUSION}

Chronic uterine inversion is a rare condition that is difficult to manage even for the experienced gynecologists. Uterine inversion has a good prognosis when managed in timely correct manner. The treatment for chronic uterine inversion is surgical that includes both abdominal and vaginal approaches. However, need for preservation of fertility excluding malignancy might be important in selected cases.

\section{Funding: No funding sources Conflict of interest: None declared Ethical approval: Not required}

\section{REFERENCES}

1. T. F. Baskett. Acute uterine inversion: a review of 40 cases. J Obstet Gynecol Can. 2002;24:953-6.

2. Simms-Stewart D, Frederick S, Fletcher H, Char G, and Mitchell S. Postmenopausal uterine inversion treated by subtotal hysterectomy. J Obstet Gynecol. 2008;28(1):116-7.

3. Lupovitch A, England ER, and Chen R. Nonpuerperal uterine inversion in association with uterine sarcoma: case report in a 26-year-old and 
review of the literature. Gynecol Oncol. 2005;97(3):938-41.

4. C. G. Salomon, S. K. Patel. Computed tomography of chronic nonpuerperal uterine inversion. J Comput Assist Tomogr. 1990;14:1024-6.

5. C. G. Salomon, S. K. Patel. Computed tomography of chronic nonpuerperal uterine inversion. J Comput Assist Tomogr. 1990;14:1024-6.
6. Racconi R, Huh WK, Chiang S. Postmenopausal uterine inversion associated with endometrial polyps. Obstet Gynecol. 2003;102:521-3.

DOI: $10.5455 / 2320-1770 . i j r \operatorname{cog} 20140644$

Cite this article as: Katke RD. Extremely rare case report of chronic inversion of uterus with submucous fundal fibroid with dragging of bladder wall and ureters along with: a case report and review of literature. Int J Reprod Contracept Obstet Gynecol 2014;3:479-82. 